\section{Public Statement on the Importance of Prevention and Management of Obesity and Metabolic Syndrome during the COVID-19 Pandemic}

\author{
Korean Society for the Study of Obesity'; Chang Beom Lee ${ }^{2, *}$ \\ ${ }^{1}$ Korean Society for The Study of Obesity, Seoul: ${ }^{2}$ Division of Endocrinology and Metabolism, Department of \\ Internal Medicine, Hanyang University Guri Hospital, Hanyang University College of Medicine, Guri, Korea
}

\author{
Received July 28, 2021 \\ Reviewed August 31, 2021 \\ Accepted September 1, 2021 \\ *Corresponding author \\ Chang Beom Lee \\ https://orcid.org/0000-0003-4891-834X \\ Division of Endocrinology and \\ Metabolism, Department of Internal \\ Medicine, Hanyang University Guri \\ Hospital, Hanyang University College of \\ Medicine, 153 Gyeongchun-ro, \\ Guri 11923, Korea \\ Tel: +82-2-364-0886 \\ Fax: +82-2-364-0883 \\ E-mail: lekang@hanyang.ac.kr
}

The first case of coronavirus disease 2019 (COVID-19) was reported in December 2019, and the virus has since resulted in more than 210 million cases and 4.5 million deaths worldwide. In Korea, since the first COVID-19 case in January 2020, more than 85,000 confirmed cases and 1,500 deaths have been reported. ${ }^{1}$ The World Health Organization declared COVID-19 a pandemic on March 11,2020 , imploring the global society to redirect its resources toward treatment and control of COVID-19. ${ }^{2}$

"Social distancing," a social agreement and effort to minimize mass infection, is an important precaution to prevent COVID-19 infection and spread. However, social distancing entails irregular living habits as well as reduced physical activity through restricting or limiting access to facilities for sports, physical fitness, and exercise, which increases the risk of lifestyle-related diseases such as obesity and metabolic syndrome. Therefore, caution is necessary while adapting to these limitations as several cross-sectional studies $^{3,4}$ have shown that the COVID-19 pandemic is associated with increased risk of obesity in children and adults. Considering these critical circumstances, we recommend some issues for prevention and management of obesity and metabolic syndrome in the COVID-19 pandemic.
First, it is crucial to maintain or increase levels of regular physical activity while practicing COVID-19 preventive measures. A sufficient amount of physical activity can help resolve accumulated body fat and facilitate effective weight management. In addition to reducing the prevalence of obesity-related diseases and improving immunity against viral infections, several studies have reported positive effects of exercise and adequate physical activity for controlling chronic illnesses such as hypertension and diabetes.

Second, adopting a regular and balanced diet with appropriate portions is necessary for maintaining healthy lifestyle and weight. In addition, to minimize a high calorie or imbalanced nutrient intake due to unhealthy dietary habits, consumption of excessively sugary, fatty, and salty food items must be limited.

Third, we recommend regular medical visits for people suffering from chronic conditions. Although chronic illnesses require frequent medical care, health check-ups and drug prescriptions, people with chronic disease have been categorized as "COVID-19 high-risk groups," resulting in postponed visits and delayed medical treatment. Since the outbreak of COVID-19, health care services have been concentrated on its prevention and treatment, resulting in neglect and mismanagement of other chronic illnesses. Chronic

Copyright @ 2021 Korean Society for the Study of Obesity

(a) This is an Open Access article distributed under the terms of the Creative Commons Attribution Non-Commercial License (https://creativecommons.org/licenses/by-nc/4.o/) which permits unrestricted non-commercial use, distribution, and reproduction in any medium, provided the original work is properly cited. 
diseases such as obesity, hypertension, and diabetes show no symptoms in the early stages and are known as "silent killers." Without timely treatment and sustained care, chronic illnesses can exacerbate and cause life-threatening complications such as cardio-cerebrovascular diseases. In particular, National Health Examination recipients should ensure follow-up on designated checkups.

Fourth, we urge adherence to COVID-19 prevention guidelines. In particular, those with chronic illnesses such as hypertension, diabetes, and obesity are more vulnerable and prone to rapid progression of COVID-19 infection. ${ }^{5}$ Therefore, those with chronic diseases must observe preventive guidelines and take special care of their health.

Importantly, it is imperative that we follow preventive measures and practice social distancing, maintain a healthy lifestyle, and receive regular health checkups to prevent and manage obesity and metabolic syndrome as an important healthcare measure during the COVID-19 pandemic. Academic societies and associations consisting of experts in obesity and metabolic syndrome continue efforts to safeguard the health and safety of fellow Koreans.

August 30, 2021

\section{CONFLICTS OF INTEREST}

The authors declare no conflict of interest.

\section{ACKNOWLEDGMENTS}

We acknowledge the contributions of the Korean Diabetes As- socation (KDA), Korean Endocrine Society (KES), Korean Society for Exercise Nutrition (KSEN), Korean Society of Exercise Physiology (KSEP), Korean Society for Metabolic and Bariatric Surgery (KSMBS), The Korean Dietetic Association (KDA), The Korean Society of Cardiology (KSC), The Korean Society of Clinical Nutrition (KSCN), The Korean Society of Community Nutrition (KSCN), and The Korean Society of Lipid and Atherosclerosis (KSoLA) for their comprehensive review and advice.

\section{REFERENCES}

1. Ministry of Health and Welfare. Coronavirus Disease-19, Republic of Korea. Cases in Korea [Internet]. Sejong: Ministry of Health and Welfare of South Korea; 2021 [cited 2021 Aug 30]. Available from: http://ncov.mohw.go.kr/en/

2. Ducharme J. World Health Organization declares COVID-19 a 'Pandemic.' Here's what that means. The Time 2020 Mar 11.

3. Matsungo TM, Chopera P. Effect of the COVID-19-induced lockdown on nutrition, health and lifestyle patterns among adults in Zimbabwe. BMJ Nutr Prev Health 2020;3:205-12.

4. Ahmed HO. The impact of social distancing and self-isolation in the last corona COVID-19 outbreak on the body weight in Sulaimani governorate- Kurdistan/Iraq, a prospective case series study. Ann Med Surg (Lond) 2020;59:110-7.

5. Gao YD, Ding M, Dong X, Zhang JJ, Kursat Azkur A, Azkur D, et al. Risk factors for severe and critically ill COVID-19 patients: a review. Allergy 2021;76:428-55. 